\title{
Introduction to a centenary history of Australian medicine
}

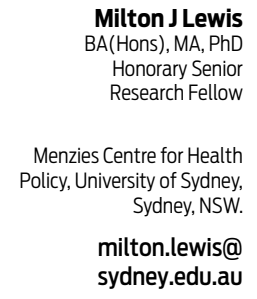

doi: 10.5694/mjal4.00422
"History is not the story of strangers ... It is the story of us had we been born a little earlier. History is memory."

- Stephen Fry, English polymath, writer, actor and TV celebrity,
launching in 2006 a campaign to promote the study of history. ${ }^{1}$

$\mathrm{y}$ any reckoning, 100 years of continuous publication is a fine record for a journal, worthy of celebration and reflection. Reflection would be richer if we had available to us a first-rate, scholarly history of medicine as it developed in Australia over the same interval or, even better, from 1788 and possibly reaching beyond into our Indigenous heritage as well. Unfortunately such a record is yet to be written. My hope is that while informative in itself, this supplement will be a step towards production of such a work; a work that would be a valuable cultural artefact that would also offer useful insights into contemporary medical and health matters.

As editor of this supplement, I chose to devote the bulk of the articles to what I have identified as key areas of modern, science-based medicine, the arrival of which we will date, for the sake of historical convention, from the late 19th century. I assigned myself the task of writing the first article, intended as a broad overview of the period from the arrival of the First Fleet to the close of the 19th century; important in its own right but also providing background to several of the other articles dealing with particular areas of medicine in the post-1900 era. My period, then, is the colonial period before the maturation of the organisationally complex, dauntingly knowledge-intensive, unprecedentedly effective and economically resource-ravenous enterprise that is modern medicine. During this interval many of the professional, cultural, social, economic and political matters relating to 20 th and 21st century health care were already emerging.

In 19th century Britain (where the great majority of Australian colonial doctors were trained), medical history was usually written by practitioners ("insiders") to throw light on contemporary therapeutic and scientific advances or to discuss the profession's values, aspirations and achievements. In the 20th century, practitioners continued to write histories. However, from the mid 20th century, a growing number of scholars trained in history, not medicine ("outsiders"), in Britain and other Western countries including Australia and, increasingly, from other parts of the world, have investigated and written on various aspects of the history of medicine. What is taken for granted by the insiders may well appear problematic to the outsiders. Moreover, the outsiders are commonly concerned not only with the internal history of medicine but with the influence on medicine of the larger context social, economic, cultural and political - in which it functions and vice versa.
The personal and technical insights that arise from the hard-won experience of insiders are invaluable. But as a member of a professional culture, the insider may suffer from blind spots in his or her perspective; and his or her understanding needs to be to be set against that of the outsider, itself sometimes limited by a priori assumptions. Western anthropologists studying foreign cultures struggled with not dissimilar epistemological problems of how to source reliable knowledge when they, as outsiders, encountered cultural insiders' explanations of things in terms of the meanings valid in the insiders' particular culture; although clearly the anthropologist is located at a much greater cultural distance than the medical historian, while the epistemological issues in anthropology are of much greater complexity.

My limited knowledge of the history of anthropology's response to this epistemological challenge leads me to think there is no easy, ultimate solution to the problem of "objectivity" in the study of human cultural groups. ${ }^{2}$ But in the meantime, back in the less fraught world of the study of medical history, I think we might reasonably hope debate between insiders and outsiders, where the strengths and limitations of each side's perspective are acknowledged, will lead to a richer understanding of the historical development of medicine.

Apart from my article there are eight special-subject articles focused on modern, science-based medicine in the post-1900 era. The areas of medicine they cover by no means exhaust what might be addressed if word limits were not so tight. The inclusion of articles, on the history of general practice, the medical specialties, medical education, medical research and the health experience of Indigenous people is unremarkable. But the inclusion of the other three articles - two on the changing burden of disease (infectious diseases and non-communicable diseases) and the early history of the Pharmaceutical Benefits Scheme requires some explanation. The first two (on the changing pattern of diseases) describe the major health transition to which doctors have had to respond over the past century or so. The article on the origins of the Pharmaceutical Benefits Scheme is included partly because the origins are not often discussed and in part because it raises policy issues that a larger history of health policy (on which we do not have an article) would more extensively explore.

Half a century ago Bryan Gandevia (1925-2006), prolific insider medical historian and compiler of a pioneering bibliography of the history of medicine in Australia, identified the first article on the history of Australian medicine as one published in 1891 in the Australasian Medical Gazette, a New South Wales-based forerunner of the Medical Journal of Australia. ${ }^{3}$ Gandevia reported that in his bibliographical quest he had located about 500 articles relevant to the history of Australian medicine published after the 1891 article. He paid tribute to the "generous policy" of the $M J A$ for making possible the publication of most of these 
articles. ${ }^{4}$ It seems fitting, then, that all this time later the $M J A$ should generously agree to publish this centenary history supplement.

Competing interests: No relevant disclosures.

Provenance: Commissioned; externally peer reviewed.
1 Fry S. The future's in the past. The Observer (London) 2006; 9 Jul. http:// www.theguardian.com/theobserver/2006/jul/09/featuresreview.review (accessed Feb 2014).

2 Harris M. History and significance of the emic/etic distinction. Ann Rev Anthropol 1976; 5: 329-350.

3 Hankins GT. The history of medicine in Sydney from the early times to the year 1833. Australasian Medical Gazette 1890/91; 10: 194-202.

4 Gandevia B. The pattern of Australian medical history. Proc R Soc Med 1957; 50: $591-598$ 